of fluorite (combined, no doubt, with a momentary lapse of memory) has betrayed him into putting it in twice, as Fig. 125 on p. 337 and as Fig. 235 on p. 736.

This, in short, is a chemical work of that rare kind which is both scholarly and humane, and as such it may be commended warmly and without reserve to all serious students of the science and to those who may influence their reading.

\section{Physics and Chemistry of the Soil.}

The Soil: an Introduction to the Scientific Study of the Growth of Crops. By Sir A. D. Hall. Fourth edition, revised and enlarged. Pp. xvii +388 . (London: John Murray, 1931.) 9s. net.

THE reissue of this well-known textbook will 1 be welcomed by all engaged in agricultural teaching. Appearing first in 1903, it had passed through three editions, with many reprints, by 1920, and has now reached a fourth edition. These facts alone indicate plainly the welcome given to the book in the past, and the reason for this is not far to seek. It demands no wide knowledge of the pure sciences on the part of the reader. It accepts the average student of agriculture as his lecturer generally finds him - a man anxious to know something of the fundamental scientific facts underlying his profession but by force of circumstances quite unable to undertake a thorough scientific training before beginning his more technical studies.

As the author stated in his original introduction, the book is " primarily intended for the students of our agricultural colleges and schools, and for the farmer who wishes to know something about the materials he is handling day by day". This purpose it serves admirably, but its use need not be limited to this type of reader. A teacher might well put it into the hands of the budding agricultural chemist, after his training in pure science, as a general survey of our knowledge of the soil. To such a student its extremely readable character makes it a useful introduction to the more highly specialised publications dealing with particular aspects of the subject.

The new edition follows fairly closely the general lines of previous issues, though a considerable amount of new material has been incorporated. Starting with a description of the soil-forming processes, the author deals successively with the physical and chemical properties of the soil, the soil micro-organisms and the processes dependent on them, the retention of fertilisers, base exchange, the loss of soil constituents by leeching, soil acidity, causes of fertility and sterility in soils, and, finally, the classification of soils into types. Never losing sight of his original object, the author brings each subject within the grasp of the reader he has in view and illustrates the general principles by an abundance of examples from both scientifically controlled field experiments and farming practice.

It is interesting to note the infiltration of recent advances in soil science into a book of this type. Extensive treatment of such subjects as soil colloids, hydrogen ion concentrations, soil profiles, and the classification of soils founded on the work of the Russian school would obviously have been impossible, but each of these subjects receives mention and finds its place amongst the older material.

A short bibliography, useful to the student as a guide to wider reading, has been added, and its value is enhanced by the care which has been taken in the selection of the items. A short index completes the volume.

As might be expected, the book is excellently produced and is singularly free from errors. The volume in its new form certainly maintains the high position it has made for itself in the past.

\section{H. A. D. Nevilue.}

\section{Fundamentals of Ophthalmology}

Text-Book of Ophthalmology. By Dr. W. Stewart Duke-Elder. Vol. 1: The Development, Form and Function of the Visual Apparatus. Pp. xxix $+1124+7$ plates. (London : Henry Kimpton, 1932.) 63s. net.

7 THERE have been several good manuals of 1 ophthalmology written by Englishmen. The first of the modern, that is, post-ophthalmoscopic, period was written by the late Mr. Edward Nettleship. It was a very remarkable book, which, like its contemporary, Gowers's "Medical Ophthalmoscopy ", well merits perusal even to-day, for it is packed with the observations of a very great scientific clinician. Doubtless a larger and more comprehensive textbook would have been written in due course if it had not been for the appearance of Fuchs's textbook, which was soon translated into English and is still universally read. The English version was edited and published in America, and has undergone transformations in later editions which are not all improvements. As so often occurs, ill-digested new material has been invaginated into the text in such a manner as to obscure its balance and perspective without making it satisfactorily encyclopædic The

No. 3263, VoL. 129] 